\title{
Landscape analysis: Preventing and managing pre-eclampsia and eclampsia in Pakistan
}

Population Council

Follow this and additional works at: https://knowledgecommons.popcouncil.org/departments_sbsr-rh

Part of the Demography, Population, and Ecology Commons, Family, Life Course, and Society Commons, International Public Health Commons, and the Maternal and Child Health Commons How does access to this work benefit you? Let us know!

\section{Recommended Citation}

"Landscape analysis: Preventing and managing pre-eclampsia and eclampsia in Pakistan," Ending Eclampsia Country Brief. Washington, DC: Population Council, 2017. 


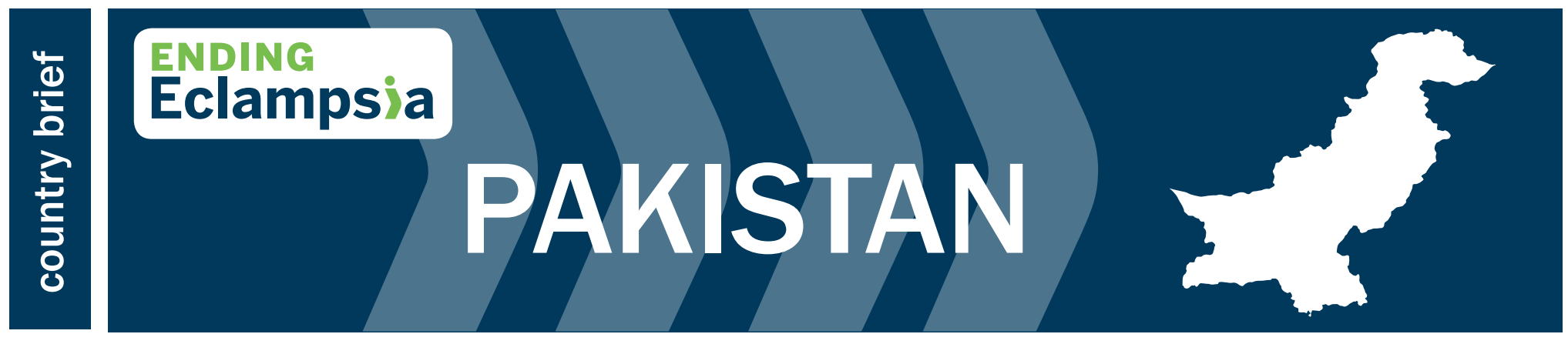

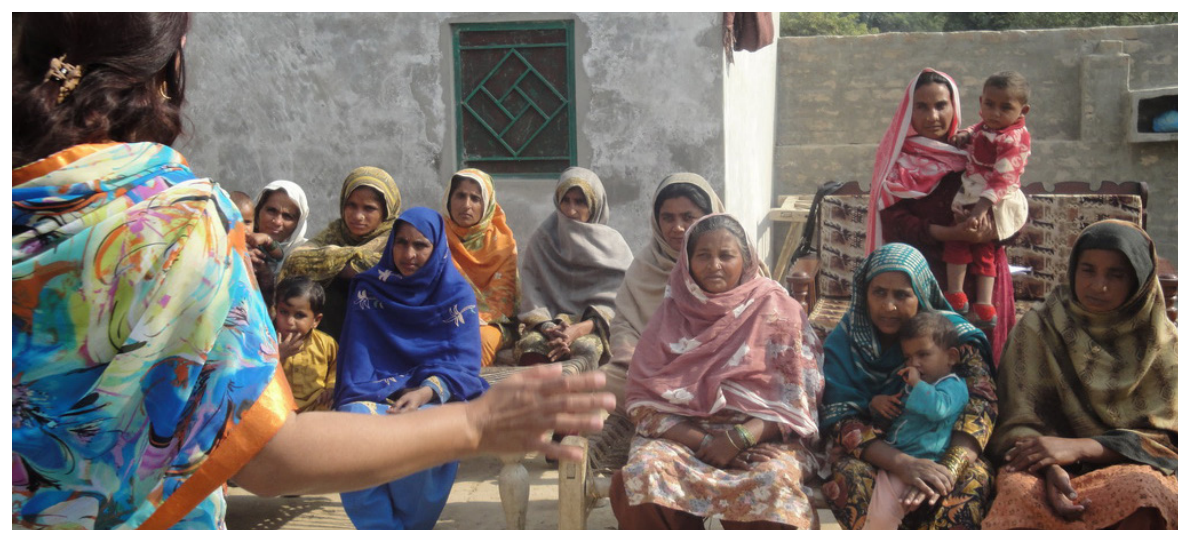

\section{LANDSCAPE ANALYSIS: PREVENTING AND MANAGING PRE-ECLAMPSIA AND ECLAMPSIA IN PAKISTAN}

Maternal mortality remains a major challenge to health systems worldwide and Pakistan is among the six countries where more than fifty percent of the world's maternal deaths occur. According to the World Health Organization and UNICEF, every year 18 percent of maternal deaths are caused by pre-eclampsia and eclampsia (PE/E). The 2007 Pakistan Demographic and Health Survey found that eclampsia caused 11 percent of direct maternal deaths and is the third leading cause of maternal mortality. Another study conducted by the Population Council revealed that in Punjab, a quarter of maternal deaths were from eclampsia.

For managing and treating PE/E in Pakistan, magnesium sulphate $\left(\mathrm{MgSO}_{4}\right)$ has been registered for use since 2007 and is included in the essential medicines lists for all provinces and regions. Management of eclampsia and use of $\mathrm{MgSO}_{4}$ guidelines, protocols, and training manuals for various cadres of providers have been developed and provider trainings on improving maternal, newborn, and child health (MNCH) capacity and referrals are underway.

\section{OBJECTIVE AND METHODS}

The Ending Eclampsia project conducted a landscape analysis to identify policy and program activities, as well as gaps and challenges around the prevention and treatment of $\mathrm{PE} / \mathrm{E}$ and use of $\mathrm{MgSO}_{4}$ at the provincial and district levels in Pakistan. The analysis assessed the practices for $\mathrm{PE} / \mathrm{E}$ prevention and treatment, prevalence of $\mathrm{PE} / \mathrm{E}$, associated complications, and contribution to maternal mortality and morbidity. Methods included interviews with service providers, provider-client observations during antenatal care visits, exit interviews, and rapid situation assessment of health facilities for readiness to provide maternal and newborn health (MNH) services. Overall, 24 facilities were visited, 11 in district Thatta of Sindh Province and 13 in district Chakwal of Punjab Province.

\section{Highlights}

- Pre-eclampsia (PE) is a condition in pregnant women marked by high blood pressure and protein in urine after 20 weeks gestation.

- High-quality antenatal care can prevent or detect preeclampsia at an early stage, and prevent its progression to eclampsia.

- Women in developing countries are 300 times more likely to die from eclampsia than women in developed countries.

- Pre-eclampsia and eclampsia can be managed by administering antihypertensive drugs and magnesium sulfate $\left(\mathrm{MgSO}_{4}\right)$.

- $\mathrm{MgSO}_{4}$ is the safest and most effective drug for controlling seizures, and is one of the $13 \mathrm{UN}$ Life-Saving Commodities for Women and Children.

- $\quad$ PE/E and other hypertensive disorders in pregnancy increase the risk of pre-term births.
The Population Council conducts research and delivers solutions that improve lives around the world. Big ideas supported by evidence: It's our model for global change. popcouncil.org

(C) 2017 The Population Council, Inc
POPULATION COUNCIL

Ideas. Evidence. Impact.

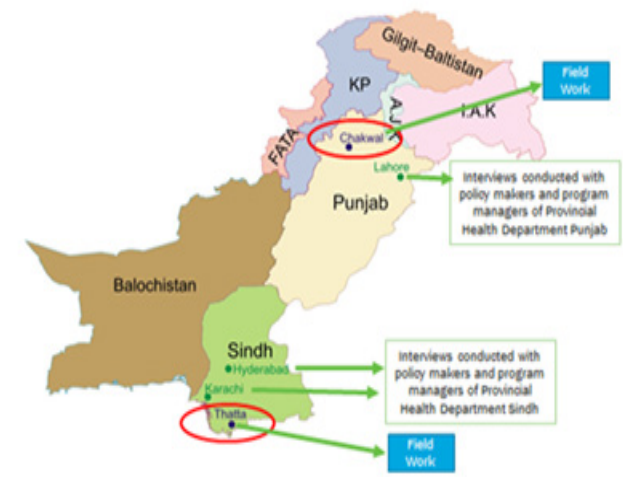




\section{FINDINGS}

\section{Commodities and essential equipment}

Certain essential equipment and commodities are needed for providing PE/E services. Dipsticks for testing proteinuria were unavailable in three rural health centers and basic health units. Availability of patella hammers required for diagnosing $\mathrm{MgSO}_{4}$ toxicity was low, and calcium gluconate for managing $\mathrm{MgSO}_{4}$ toxicity was only found in one-third of facilities. Of the 24 facilities, 14 had syringes for $\mathrm{MgSO}_{4}$ administration.

\section{Guidelines, protocols, and training}

Slightly more than half of providers were trained on maternal health, family planning, or child health during the last three years. One-third of doctors and two-thirds of other providers (paramedics) received training. Of those trained, more doctors had received training in emergency obstetric care, compared to other providers. All other providers were trained in antenatal care, safe delivery, and postnatal care.

Availability of guidelines and protocols for use of $\mathrm{MgSO}_{4}$ also varied. All secondary facilities had them, but few facilities had guidelines or protocols available for administering a loading dose of $\mathrm{MgSO}_{4}$ to women with PE/E.

\section{Provider knowledge of prevention and management}

Doctors had better knowledge compared to other providers of hypertensive disorders. More than four-fifths of doctors and other providers correctly diagnosed eclampsia (85 and 83 percent, respectively). More than two-thirds of doctors and three-fifths of other providers can diagnose severe pre-eclampsia, while four-fifths of doctors and half of the other service providers correctly diagnosed chronic hypertension.

Service providers' knowledge of risk factors, including history of hypertension, diabetes, obstetric history, and maternal age was assessed during observations of ANC consultations. Only three percent of providers looked for risk factors, while none of the other providers assessed risks.

Urine tests for protein, glucose, albumin, and hemoglobin are essential for diagnosing PE/E and other obstetric complications. During the ANC consultations, 6 percent of providers advised testing urine for protein, glucose, and albumin. Blood tests were performed by a quarter of the service providers.

Very few service providers use aspirin as prophylaxis for preventing $\mathrm{PE} / \mathrm{E}$. One-fourth of service providers use aspirin prophylaxis, less than half of doctors and one-tenth of other providers reported the practice.

Physical examinations were inconsistent among providers. Three-fourths of all providers checked blood pressure, onethird checked for anemia, and one-tenth of providers examined clients for signs of edema. Nearly a quarter recorded their observations on the client's ANC card.
Controlling impending convulsions in severe pre-eclampsia and eclampsia with anticonvulsants is a life-saving intervention for mothers and babies. Service providers were asked if they knew the loading and maintenance doses of $\mathrm{MgSO}_{4}$ as defined by the Pritchard Regime. Overall, 45 percent of doctors and 17 percent of other providers correctly knew the loading dose; 45 percent of doctors and 13 percent of other providers correctly knew the maintenance dose.

\section{Practices for $\mathrm{MgSO}_{4}$ use}

Service providers were asked about their current practices in use of $\mathrm{MgSO}_{4}$, the supply of $\mathrm{MgSO}_{4}$ its availability at their facility, use of alternative drugs to control convulsions, and barriers to $\mathrm{MgSO}_{4}$ use. Only 15 percent of all providers (25 percent of doctors and 9 percent of other providers) reported current use of $\mathrm{MgSO}_{4}$. Of those, 40 percent reported having a sufficient supply, while nearly half had inadequate supply, and 12 percent were unaware of the supply in their facility.

\section{CONCLUSION}

This landscape analysis was a major study and one of the first of its kind in in the country, blending multiple perspectives on provision of care through the public health system for pregnant women facing, or at risk of, PE/E. Through this analysis, the Ending Eclampsia project identified a number of basic infrastructural weaknesses. A positive finding, however, was that protocols for preventing and managing eclampsia have been developed and are widely available at all health facilities. However, protocols on how to administer $\mathrm{MgSO}_{4}$, although developed, have still not been widely distributed.

\section{RECOMMENDATIONS}

- $\quad$ Develop competency-based MNCH trainings for all providers on enhancing provider competence in the use of $\mathrm{MgSO}_{4}$. The strategy should include schedules for new and refresher trainings, onsite training approaches, and a mechanism for assessing competence.

- $\quad$ Develop guidelines for PE/E prevention that include aspirin prophylaxis for management of moderate and severe hypertension with antihypertensive drugs.

- Distribute PE/E management protocols, especially administration methods for $\mathrm{MgSO}_{4}$, to ensure they are universally available and prominently displayed in facilities.

\section{CONTACT}

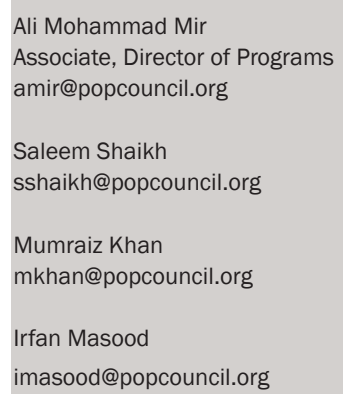

